\title{
Panagrellus redivivus: um promissor nematoide para aulas práticas de Biologia
}

\section{celular}

\author{
Panagrellus redivivus: a promising nematode for cell biology practical classes \\ Panagrellus redivivus: un nematodo prometedor para lecciones prácticas en Biología Celular
}

Recebido: 11/01/2022 | Revisado: 19/01/2022 | Aceito: 24/01/2022 | Publicado: 25/01/2022

\author{
Larissa Stefanello \\ ORCID: https://orcid.org/0000-0002-8076-3897 \\ Universidade Federal de Santa Maria, Brasil \\ E-mail: stefanellolari14@gmail.com \\ Elgion Lucio da Silva Loreto \\ ORCID: https://orcid.org/0000-0002-7586-8168 \\ Universidade Federal de Santa Maria, Brasil \\ E-mail: elgion@base.ufsm.br
}

\begin{abstract}
Resumo
A teoria celular condensa estudos sobre origem, composição e funcionamento das células. Os primeiros contribuintes dessa teoria foram Matthias Schleiden e Theodor Schwann que, por meio de seus estudos, concluíram que todos os seres vivos são formados por células. A compreensão de conceitos básicos de biologia celular é fundamental para o aprendizado da fisiologia, reprodução, hereditariedade, propagação de doenças e interações entre os seres vivos. Por isso, do ensino fundamental ao ensino médio, as disciplinas de ciências abordam tópicos de citologia. Todavia, esses são tratados de forma predominantemente teórica. Aulas práticas são extremamente importantes para a alfabetização científica e devem ser realizadas desde o ensino básico. Contudo, há uma carência de experimentos que permitam a visualização de células animais em tecidos vivos. Frente a isso, esse artigo propõe uma aula prática, utilizando o verme Panagrellus redivivus, com o objetivo de elucidar a multicelularidade, bem como a formação de novas células e do ser vivo por meio da embriogênese. Esse nematoide é de fácil obtenção e o manuseio é feito utilizando materiais de baixo custo, mas o ganho em aprendizagem é muito alto. Acredita-se que a utilização desse modelo experimental não só facilite o entendimento do tópico proposto, como também auxilie e incentive a formação científica dos discentes.
\end{abstract}

Palavras-chave: Multicelularidade; Teoria celular; Prática de citologia; Embriogênese.

\begin{abstract}
Cell theory condenses studies on the origin, composition and functioning of cells. The first contributors to this theory were Matthias Schleiden and Theodor Schwann who, through their studies, concluded that all living beings are made up of cells. The understanding of basic concepts of cell biology is fundamental for the learning of physiology, reproduction, heredity, propagation of diseases and interactions between living beings. Therefore, from elementary school to high school, science subjects cover cytology topics. However, these are treated in a predominantly theoretical way. Practical classes are extremely important for scientific literacy and should be carried out from basic education onwards. However, there is a lack of experiments that allow the visualization of animal cells in living tissue. In view of this, this article proposes a practical class using the worm Panagrellus redivivus in order to elucidate multicellularity as well as the formation of new cells and the living being through embryogenesis. This nematode is easy to obtain and handling is done using low-cost materials, but the learning gain is very high. It is believed that the use of this experimental model not only facilitates the understanding of the proposed topic but also helps and encourages the scientific training of students.
\end{abstract}

Keywords: Multicellularity; Cell theory; Cytology practice; Embryogenesis.

\section{Resumen}

La teoría celular condensa los estudios sobre el origen, composición y funcionamiento de las células. Los primeros contribuyentes a esta teoría fueron Matthias Schleiden y Theodor Schwann quienes, a través de sus estudios, concluyeron que todos los seres vivos están formados por células. La comprensión de conceptos básicos de biología celular es fundamental para el aprendizaje de la fisiología, la reproducción, la herencia, la propagación de enfermedades y las interacciones entre los seres vivos. Por lo tanto, desde la escuela primaria hasta la secundaria, las materias de ciencias cubren temas de citología. Sin embargo, estos son tratados de una manera predominantemente teórica. Las clases prácticas son de suma importancia para la alfabetización científica y deben llevarse a cabo desde la educación básica en adelante. Sin embargo, faltan experimentos que permitan la visualización de células animales en tejido vivo. Ante esto, este artículo propone una clase práctica utilizando el gusano Panagrellus redivivus con el fin de 
dilucidar la pluricelularidad así como la formación de nuevas células y del ser vivo a través de la embriogénesis. Este nematodo es fácil de obtener y su manejo se realiza con materiales de bajo costo, pero la ganancia de aprendizaje es muy alta. Se cree que el uso de este modelo experimental no solo facilita la comprensión del tema propuesto sino que también ayuda y fomenta la formación científica de los estudiantes.

Palabras clave: Pluricelularidad; Teoría celular; Práctica de citología; Embriogénesis.

\section{Introdução}

A Teoria celular é um dos pilares do estudo da biologia. Seus postulados são fruto do estudo e contribuição de muitos pesquisadores dos quais se destaca a invenção do microscópio no século XVII. Contudo, a emergência da biologia celular como ciência ocorre a partir das publicações do botânico Matthias Schleiden, em 1838, e do zoólogo Theodor Schwann, em 1839 (Alberts, et al., 2017). A partir de investigações sistemáticas realizadas por ambos, tanto em células vegetais quanto animais, concluiu-se que a célula é a unidade básica de todo ser vivo. Além disso, seus trabalhos e o de outros microscopistas do século XIX lentamente conduziram à compreensão de que todas as células vivas são formadas pelo crescimento e divisão de células pré-existentes (Alberts, et al., 2017). A compreensão desses conceitos básicos é fundamental para o entendimento do funcionamento de qualquer organismo, em maior escala, isso significa entender a fisiologia, reprodução, hereditariedade, propagação de doenças e interações entre os seres vivos. Por isso, a importância do ensino de biologia celular ainda na educação básica (Carlan et al., 2014).

Entretanto, ensinar sobre uma estrutura complexa e invisível a olho nu, como a célula, constitui um desafio para muitos educadores (Paim et al., 2021). Fato agravado frente ao método de ensino característico da educação básica no Brasil: aulas teórico-expositivas com aulas práticas realizadas com pouca ou nenhuma frequência. Gaspar (2015) destaca que a atividade experimental tem vantagens sobre a teórica, porém ambas devem caminhar juntas, pois uma é o complemento da outra. No estudo da biologia celular, a realização de aulas práticas é fundamental para o entendimento da estrutura e organização das células. Um estudo feito por Oliveira, et al. (2019) evidencia que a utilização de aulas práticas de microscopia leva a um aumento significativo da compreensão dos conteúdos de citologia por parte dos estudantes. Com o uso de experimentos as aulas podem tornar-se diferenciadas e atraentes, dando a elas um processo mais dinâmico e prazeroso. A utilização de experimentos e a observação direta de objetos e fenômenos naturais são indispensáveis para a formação científica em todos os níveis de ensino (Souza, 2013).

A realização de aulas práticas de biologia celular possui, entretanto, alguns empecilhos. A obtenção de materiais de baixo custo, fácil manuseio e que promova boa eficiência de aprendizagem é um deles. Fernandes et. al. (2017) apresentam uma compilação de aulas práticas envolvendo materiais simples que permitem a visualização de diferentes tipos de células. Entre elas, a fácil observação da composição pluricelular em plantas, fazendo uso da epiderme do catafilo de cebola, da epiderme de pimentão ou folha de Elodea sp. Por outro lado, a microscopia de células animais eucariontes é mais restrita. Uma das possibilidades apresentada pelos pesquisadores é a utilização de células descamadas da mucosa bucal. Contudo, essa opção mostra células isoladas fora de seu tecido de origem, o que pode ser um bom exemplo para a demonstração da estrutura celular geral, mas é pouco eficiente para evidenciar a estrutura pluricelular. Outra opção é recorrer às lâminas permanentes, porém, essas são de difícil confecção, uma vez que envolvem coleta do material, fixação, clivagem, processamento, inclusão, microtomia (corte) e coloração (Caputo et al., 2010). Dessa forma, sua utilização em aulas do ensino básico priva o aluno de parte do processo de construção do conhecimento científico. Uma vez que as diversas atividades no ensino de ciências pressupõem a interação dos alunos com os conteúdos científicos, dos alunos com materiais, recursos e procedimentos de sistematização e de comunicação dos conhecimentos (Souza, 2013).

Neste estudo, propomos um modelo promissor para o estudo prático da biologia e da teoria celular. Por meio do nematoide Panagrellus redivivus é possível realizar aulas práticas que possibilitem a visualização da estrutura celular e da pluricelularidade em um animal eucarionte. O material dispensa fixação, corte e coloração, sendo assim, de fácil manuseio. Por 
isso, o aluno é capaz de acompanhar e realizar a totalidade do processo de confecção da lâmina para microscopia, construindo seu conhecimento "científico" de forma integral. Borges e Alencar (2009) ressaltam que metodologias ativas de aprendizagem, tais como proposto nessa atividade, devem favorecer a autonomia do educando, despertando a curiosidade, estimulando tomadas de decisões individuais e coletivas.

Panagrellus redivivus é uma das quinze espécies do gênero Panagrellus (Ferris, 2009; Abolafia et al., 2016; Ivanova et al., 2018) da família Panagrolaimidae e ordem Rhabditida (Nadler, et al., 2006). São organismos vermiformes, não segmentados, de coloração clara, com tamanho médio corporal entre $1,5 \mathrm{~mm}$ e cerca de $50 \mu \mathrm{m}$ de diâmetro, com cauda pontiaguda e a boca arredondada (Stock \& Nadler, 2006). Suas características corporais como, por exemplo, a sua transparência permitem, com o auxílio do microscópio ótico, a visualização de suas células sem a necessidade de coloração. Outrossim, seu tamanho diminuto possibilita uma visão completa do organismo pluricelular.

Em geral, os organismos do gênero Panagrellus possuem desenvolvimento rápido e passam por quatro estágios antes de chegar à fase adulta (Hechler, 1970). Reproduzem-se de forma sexuada e apresentam altas taxas reprodutivas. São vivíparos com embriogênese e eclosão ocorrendo dentro do útero (Freitas, 2017). Fêmeas mais velhas possuem ovos em todos os estágios de desenvolvimento, com os mais avançados perto da vulva (Hechler, 1970). Sendo assim, a observação da embriogênese por meio da microscopia ótica é perfeitamente possível e o aluno consegue acompanhar a formação de novas células a partir de células pré-existentes, postulado da teoria celular.

$P$. redivivus são nematoides de vida livre e não parasitas. São amplamente empregados na alimentação de várias espécies de peixes e camarões, como camarão da areia (Crangon crangon), camarão juvenil rei (Penaeus blebejus), carpa comum (Cyprinus carpio) e carpa prateada (Hypophthalmichthys molitrix) (Lavens \& Sorgeloos, 1996). Estudos feitos por Focken et al. (2006) mostram P. redivivus como um bom substituto para Artemia na criação larval do camarão de patas brancas (Litopenaeus vannamei). Resultados semelhantes aos encontrados por Sautter et al. (2007), onde o verme mostrou-se como uma dieta adequada para a criação da espécie ornamental Synodontis petricola, popularmente conhecido como peixegato. A utilização de P. redivivus como alimento de peixes e camarões ocorre em detrimento da Artemia sp., espécie com variações na taxa de eclosão (Sorgeloos, 1980) e alto custo (Radwin \& Rouse, 1990). Frente a essa popularização, esses nematoides são facilmente encontrados em lojas de aquariofilia e, também no E-commerce, procurando-se por "microvermes da aveia”. Logo, P. redivivus constitui-se como um material didático de fácil acesso por parte dos educadores que desejam utilizá-lo em suas aulas de biologia celular.

Concomitante a sua fácil obtenção, $P$. redivivus também são cultivados de forma simples. Um grande número desse nematoide pode ser facilmente cultivado em um laboratório com o mínimo de esforço e equipamento, ou até mesmo em casa. Radwin e Rouse (1990) testaram seis substratos comumente disponíveis como meio de crescimento para P. redivivus. Os pesquisadores usaram três substratos de baixa proteína: farinha de trigo (10,8\% de proteína), aveia (11\% de proteína) e fubá ( $8,9 \%$ de proteína). Além de dois substratos de alta proteína: farelo de algodão ( $41 \%$ de proteína) e a ração de camarão (40\% de proteína). O sexto substrato testado foi de farinha de trigo com suplementação semanal de fermento de padeiro diluído em água. Os resultados revelam que a maior produção de $P$. redivivus ocorreu nos meios de baixa proteína sendo a farinha de trigo e a aveia os mais promissores, respectivamente. A suplementação com levedura no meio contendo farinha de trigo ocasionou um leve aumento na produção dos vermes. Essa pesquisa evidência que o cultivo de $P$. redivivus é muito simples e pode ser feito com farinha de trigo ou aveia e água. Os vermes podem ser mantidos em recipientes plásticos na temperatura ambiente ou a $20^{\circ}-23^{\circ} \mathrm{C}$. Nessas condições, as culturas podem sobreviver de 33 a 56 dias (Radwin \& Rouse, 1990).

Sendo assim, uma cultura de $P$. redivivus é perfeitamente viável de ser realizada e mantida nos laboratórios (ou salas específicas) das escolas públicas e privadas uma vez que são de fácil obtenção e baixo custo. Podem ser mantidos em recipientes plásticos com materiais facilmente encontrados em supermercados tais como farinha de trigo ou aveia. A 
armazenagem é feita em temperatura ambiente por longos períodos de tempo. Quando utilizado em aulas práticas, $P$. redivivus oferece grandes benefícios à aprendizagem. Possibilita que o aluno manuseie o material do inicio ao fim, de forma simples e prática, sem necessidade de cortes ou coloração. A observação das células, devido a seu tamanho e cor, é satisfatória oferecendo ao estudante uma visão integrada da teoria celular por meio da visualização da embriogênese e pluricelularidade em um animal eucarionte.

\section{Metodologia}

\subsection{Obtenção e cultivo}

Os nematoides Panagrellus redivivus foram obtidos pelo comércio eletrônico (E-commerce). Os vermes foram cultivados em meio composto por 20 gramas de farinha de aveia e 30 mililitros de água de preferência filtrada ou fervida. A mistura foi adicionada a recipientes plásticos de 100 mililitros até uma altura de um centímetro. Em seguida, uma pequena quantidade da cultura inicial foi adicionada a cada novo meio, a partir de então, as culturas são repicadas para um novo meio em intervalos de aproximadamente uma semana. As culturas foram incubadas a $20^{\circ} \mathrm{C}$, entretanto, elas podem ser facilmente mantidas a temperatura ambiente.

\subsection{Microscopia de fluorescência}

Nematoides isolados do meio de cultura foram fixados em uma solução de etanol e ácido acético glacial, na proporção de um para um, por aproximadamente 12 horas. Para visualização dos núcleos das células empregamos brometo de etídio, uma solução com concentração de $0,3 \mathrm{mg} / \mathrm{ml}$. Esta substância é um intercalante das bases do DNA.

Os vermes fixados foram removidos da solução fixadora e ressuspendidos em aproximadamente $200 \mu$ água destilada ou filtrada. $30 \mu \mathrm{l}$ da amostra foram depositados em uma lâmina de microscopia e a ela acrescentado $10 \mu l$ da solução brometo de etídio. Por fim, cobriu-se a amostra com uma lamínula e os nematoides foram observados no microscópio Olympus BX41 fluorescence microscope (Olympus, Shinjuku, Japão). As imagens foram feitas usando um filtro de absorção de $518 \mathrm{~nm}$ e de $605 \mathrm{~nm}$ para emissão.

\subsection{Microscopia de campo claro}

Panagrellus redivivus foram observados em microscopia de campo claro tanto corados com azul de metileno quanto não corados. No primeiro caso, nematoides isolados do meio de cultura foram fixados em uma solução de etanol e ácido acético glacial, na proporção de um para um, durante aproximadamente 12 horas. Posteriormente, os vermes fixados foram removidos da solução fixadora e ressuspendidos em água destilada ou filtrada. $30 \mu 1$ da amostra foram depositados em uma lâmina de microscopia e $20 \mu \mathrm{l}$ de azul de metileno $1 \%$ foram adicionados. A amostra foi deixada em repouso durante 10 minutos para possibilitar a entrada do corante nas células. Em seguida, cobriu-se a amostra com uma lamínula de vidro e o excesso de corante foi lavado. Os nematoides foram observados em microscópio Olympus BX41.

A um isolado de P. redivivus foi adicionado $400 \mu$ de hipoclorito $50 \%$ e a amostra ficou em repouso por 10 minutos. O objetivo dessa etapa é ocasionar a morte dos vermes sem afetar o desenvolvimento dos juvenis no útero das fêmeas facilitando, assim, a visualização da embriogênese. Os nematoides foram removidos do hipoclorito e ressuspendidos em $200 \mu 1$ de água destilada ou filtrada. $30 \mu 1$ da amostra foram depositadas em uma lâmina de microscopia e cobertos com uma lamínula de vidro. Os vermes foram observados em microscópio.

\subsection{Proposta de aula prática}

As aulas práticas são importantes ferramentas de fixação e sistematização do conhecimento adquirido durante as aulas 
teóricas. Contudo, são muito mais do que mero complemento da teoria. Durante a realização das aulas experimentais o aluno é convidado a investigar e a refletir sobre um fato postulado pela ciência. São momentos de integração e consolidação do conhecimento, contribuindo para a alfabetização científica ainda na infância ou adolescência.

Para Souza (2013) na aprendizagem da disciplina de Ciências, as atividades experimentais devem ser garantidas de maneira a evitar que a relação teoria - prática seja transformada numa dicotomia. Segundo o autor, as experiências despertam, em geral, um grande interesse nos alunos, além de propiciar uma situação de investigação. Quando planejadas levando em conta estes fatores, elas constituem momentos ricos no processo de ensino e aprendizagem. Frente a isso, propomos uma aula experimental abrangendo os conceitos da teoria celular, utilizando como modelo o nematoide $P$. redivivus. A duração da atividade é de duas aulas. Os públicos alvos são desde crianças do ensino básico até adolescentes do ensino médio. Os objetivos dessa aula prática são: $i$ ) observar a composição multicelular de um animal eucarionte e, ii) identificar as fases do desenvolvimento do P. redivivus desde as primeiras divisões celulares até o embrião completo.

\subsubsection{Materiais necessários}

- Panagrellus redivivus suspendidos em água;

- Lâmina para microscopia;

- Lamínula de vidro;

- Pipeta volumétrica ou de Pasteur;

- Esmalte base (esmalte de unha);

- Microscópio.

\subsubsection{Procedimentos para realização da prática}

Previamente à realização da atividade prática, o professor deverá isolar alguns nematoides do meio de cultura. Para tanto, podem ser utilizados estereomicroscópio, placa de petri, pinça e pipeta. Ou ainda os organismos podem ser ressuspendidos diretamente do meio de cultura utilizando água. Os isolados podem ser fixados em uma solução de etanol e ácido acético glacial durante 14 horas ou em hipoclorito 50\% durante 10 minutos. Posterior a fixação, os vermes são ressuspendidos em água e mantidos em temperatura ambiente até a aula prática. Sugerimos, entretanto, que os alunos sejam também apresentados aos animais vivos, visto ao microscópio, para que possam ver seus movimentos. De nossa experiência, este momento é de grande valia, pois promove motivação nos estudantes ao ver os vermes em movimento.

Para a realização da atividade, a turma pode ser dividida em equipes. Primeiramente, devem ser identificados e demonstrados os materiais a serem utilizados. Em seguida, cada aluno deve identificar uma lâmina como o nome da equipe e do material que será observado. É fundamental que, mesmo a atividade sendo realizada em equipes, para facilitar o diálogo e interação, cada aluno monte sua própria lâmina. O professor deve orientar os estudantes para que, utilizando uma pipeta, depositem uma pequena quantidade da amostra sobre a lâmina. Em seguida, a lamínula deve ser montada sobre a lâmina. Para garantir que a amostra não resseque, a lamínula pode ser selada sobre a lâmina com esmalte base, "pintando" os bordos da lamínula.

Uma vez preparadas, as amostras devem ser visualizadas em microscopia ótica. Sendo assim, os alunos podem levar sua lâmina ao microscópio. É importante que o próprio aluno faça o manuseio do aparelho, ajustando o foco e usando os aumentos necessários. A utilização de $P$. redivivus permite a observação da composição multicelular e a embriogênese.

\subsubsection{Questões propostas}

Costa e Frenedozo, 2020, consideram importante que durante a prática pedagógica o professor proporcione espaços 
para que os alunos possam trocar informações, discutir, elaborar pensamentos e opinar. Durante esses momentos novas evidências podem ser levantadas e incorporadas à discussão. Assim, o aluno é incentivado a tomar posicionamento e a refletir criticamente sobre o assunto abordado. Posto isso, propomos algumas perguntas que podem ser aplicadas pelo docente durante a aula prática para fomentar a discussão, além de potencializar e avaliar a aprendizagem dos estudantes.

1) Cite uma característica unificadora dos seres vivos.

2) Se todos os seres vivos são formados por células, então por que há organismos tão diferentes?

3) Como as células são formadas?

4) Qual a diferença entre seres vivos unicelulares e pluricelulares? Como você é? Onde estão suas células?

\subsubsection{Respostas esperadas}

Não esperamos que os alunos consigam, só com discussões em grupo, ou mesmo com uma busca rápida de informações na internet, chegar às respostas listadas abaixo. Estas respostas são um indicativo para onde o professor pode conduzir a discussão.

1) Diferentes seres vivos possuem características peculiares e únicas que permitem seu agrupamento em diferentes táxons como filo, classe, ordem, família, gênero e espécie. Contudo, segundo a teoria celular, todos os seres vivos possuem uma característica em comum: todos são formados por células.

2) Todos os seres vivos são formados por células, mas essas podem ser muito diferentes entre si. Primeiramente, alguns organismos são formados por uma única célula, outros por várias ou ainda por milhões delas. Ademais, existem diferentes tipos celulares, alguns são altamente especializados em determinadas funções. Os seres vivos pluricelulares são como um jogo de lego onde cada peça é uma célula. Essencialmente, todo o jogo é formado por blocos, mas esses variam quanto ao tamanho, cor e forma. Sendo assim, a disposição, organização e quantidade de peças empregadas formam estruturas completamente diferentes.

3) Um dos postulados mais famosos da teoria celular diz que toda célula se origina de uma célula pré-existente. Este processo é visualizado na embriogênese do $P$. redivivus. Inicialmente, uma célula formada pela fusão dos gametas, inicia sua divisão originando duas células filhas que também irão se dividir. Assim, enxergamos um numero cada vez maior de células em cada etapa da embriogênese, até a formação completa do embrião. Esse fato não é restrito aos nematoides, mas se aplica a todos os seres vivos pluricelulares. Ou seja, mesmo o mais complexo dos organismos, originou-se de uma única célula préexistente.

4) Seres unicelulares são formados por uma única célula, como é o caso das bactérias, bem como de alguns protozoários e algas. Por outro lado, há seres vivos formados por muitas células, por exemplo, as plantas vasculares, os mamíferos, as aves e os nematoides. O Homo sapiens é uma espécie pluricelular composta por trilhões de células. No corpo humano há células muito diferentes, formando os tecidos. Logo, a pele, os olhos, o cérebro, os ossos e até mesmo a cartilagem da ponta do nariz: em todas as partes do corpo existem células.

\section{Resultados e Discussão}

O meio de cultura com farinha de aveia e água foi adequado para o cultivo de $P$. redivivus. O desenvolvimento dos nematoides é rápido. No primeiro dia após a inoculação, uma densa massa se expandia pelo frasco, partindo da área central em direção à periferia. Já no quinto dia, cobriam totalmente o meio de cultura. Mesmo novas culturas sendo realizadas semanalmente, os vermes sobreviveram por, aproximadamente, 30 dias em um mesmo meio de cultura. P. redivivus pode ser mantido em um meio de baixo custo, fácil preparo e longa duração o que torna sua manutenção viável em laboratórios escolares. 
O desenvolvimento da cultura contendo $P$. redivivus durante os nove primeiros dias após a inoculação pode ser visualizado na Figura 1 e Figura 2. No primeiro dia após a inoculação (Figura 1. A) os nematoides iniciaram seu desenvolvimento do centro em direção à periferia do meio de cultura. O crescimento continuou pelo segundo (Figura 1. B), terceiro (Figura 1. C) e quarto dia (Figura 1. D). No quinto dia (Figura 1. E) os nematoides cobriram totalmente o meio. A partir do sétimo dia (Figura 1. G), alguns vermes se deslocavam pela parede do recipiente plástico até próximo a tampa. Nos dias subsequentes as características do meio mantiveram-se constantes com milhares de vermes.

Figura 1. Desenvolvimento da cultura de Panagrellus redivivus durante os nove primeiros dias após a inoculação. A. primeiro dia após a inoculação; B. segundo dia após a inoculação; C. terceiro dia após a inoculação; D. quaro dia após a inoculação; E quinto dia após a inoculação, F. sexto dia após a inoculação; G. sétimo dia após a inoculação; H. oitavo dia após a inoculação e I. nono dia após a inoculação.
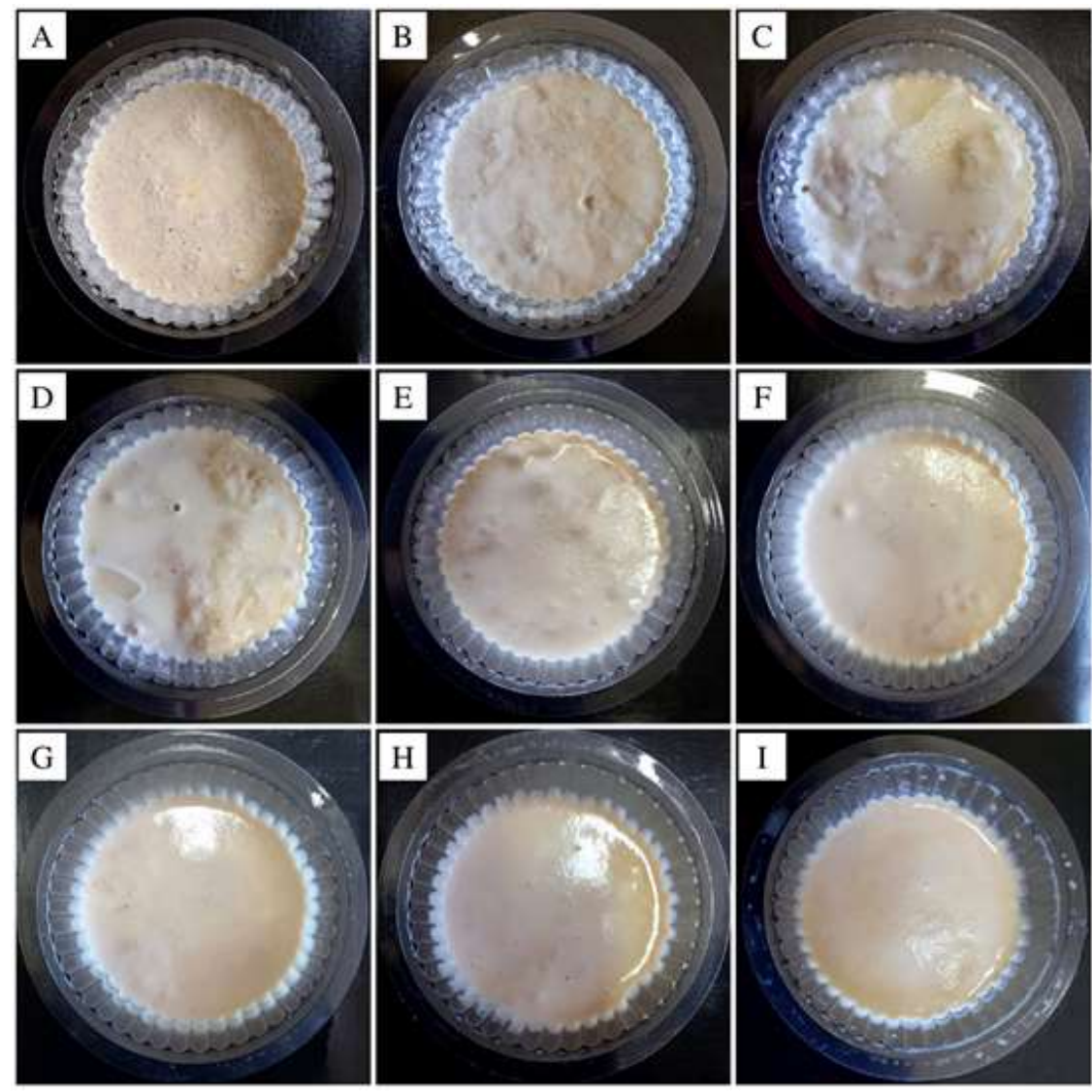

Fonte: Autores (2022). 
Figura 2. Meio de cultura para Panagrellus redivivus. Recipiente plástico de $100 \mathrm{ml}$ preenchido com meio de farinha de aveia e água até a altura de $1 \mathrm{~cm}$.

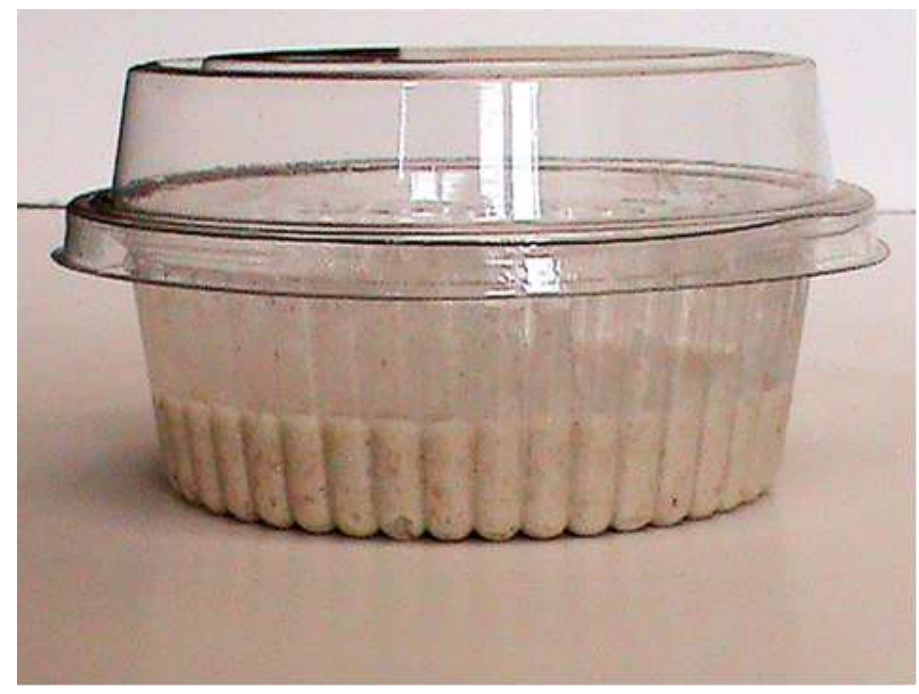

Fonte: Autores (2022).

Panagrellus spp. são organismos vermiformes, não segmentados, de coloração clara, com tamanho médio corporal de 1,5 $\mathrm{mm}$ e cerca de $50 \mu \mathrm{m}$ de diâmetro, cauda alongada semelhante a um flagelo e com a boca arredondada (Stock \& Nadler, 2006). O desenvolvimento embrionário ocorre no útero materno e quando eclodem são de tamanho diminuto (Figura 3.A). Os nematoides atingem seu maior tamanho na fase adulta (Figura 3.B).

Figura 3. Estrutura geral de um Panagrellus redivivus (objetiva 10x). A) fêmea adulta. B) juvenil.

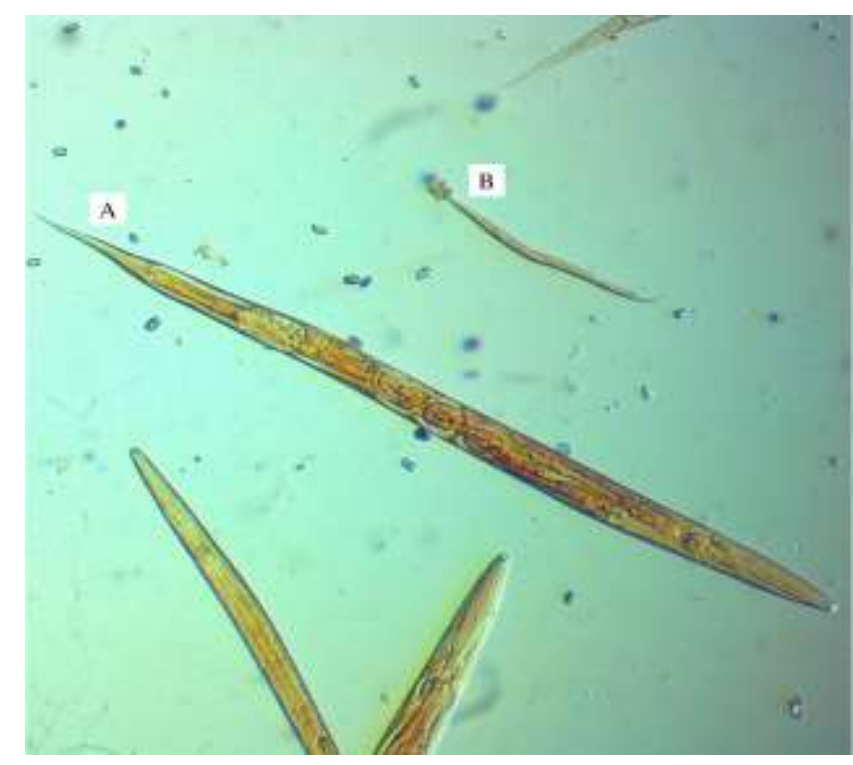

Fonte: Autores (2022).

Panagrellus são seres multicelulares que devido a sua transparência permitem a visualização de suas células. Quando observados com microscopia de campo claro, as células das gônadas dos machos adultos são bem visíveis e, devido ao seu grande tamanho, os núcleos também (Figura 4.A). As demais células constituintes do corpo de $P$. redivivus também são visualizadas, embora a visualização dos núcleos sem coloração não seja possível (Figura 4.B). 
Figura 4. Células de Panagrellus redivivus. A) células gonadais de um macho (objetiva 40x). B) células evidenciando a multicelularidade dos nemátodos (objetiva 40x).

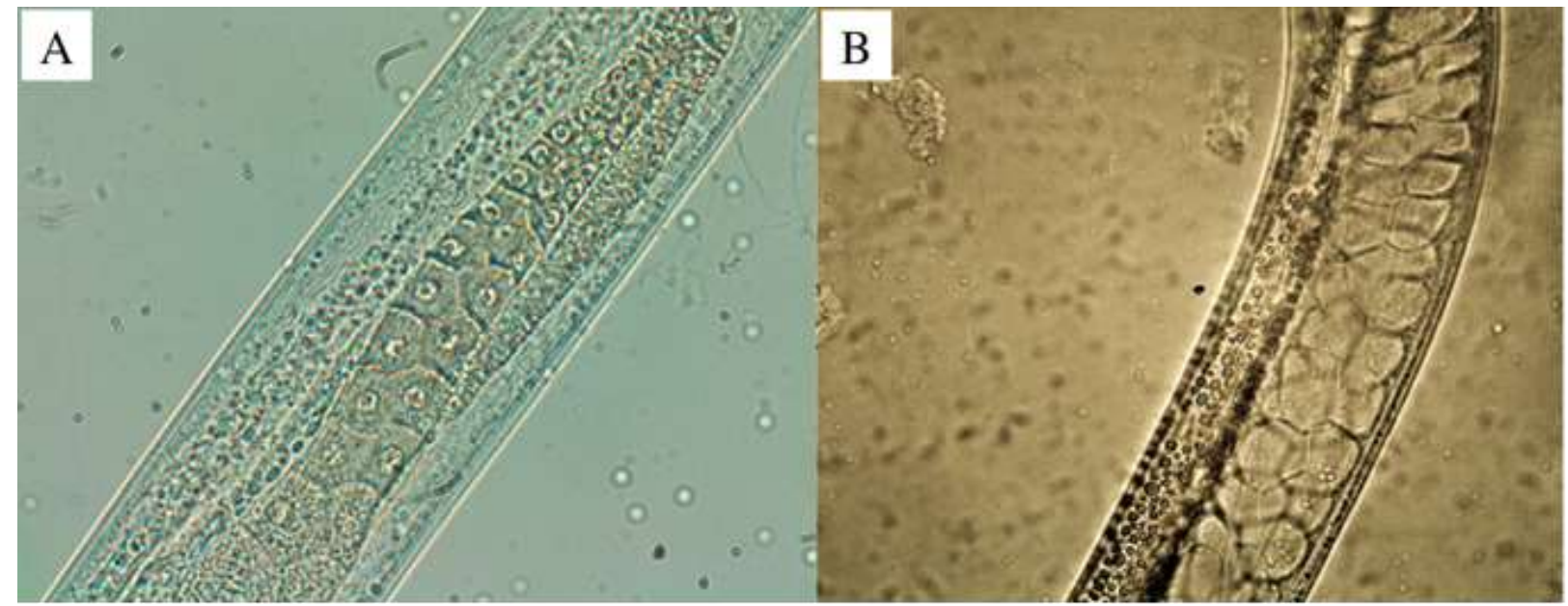

Fonte: Autores (2022).

As amostras coradas com azul de metileno possibilitaram a visualização dos núcleos da maioria das células constituintes do P. redivivus (Figura 5.A). Da mesma forma, as amostras tratadas com brometo de etídeo e observadas em microscópio de fluorescência mostram, de forma clara, os núcleos e composição multicelular do nematoide (Figura 5.B). Infelizmente, a utilização desse intercalante de DNA em aulas práticas no ensino básico é inviável devido a sua genotoxicidade (cancerígeno). Além, é claro, que nem sempre há disponibilidade de microscópio de fluorescência.

Figura 5. Células de Panagrellus redivivus. A) células gonadais de um macho coradas com azul de metileno (objetiva 40x). B) células de $P$. redivivus coradas com brometo de etídio (objetiva 20x), neste último, os núcleos são visíveis como pontos brilhantes vermelhos.

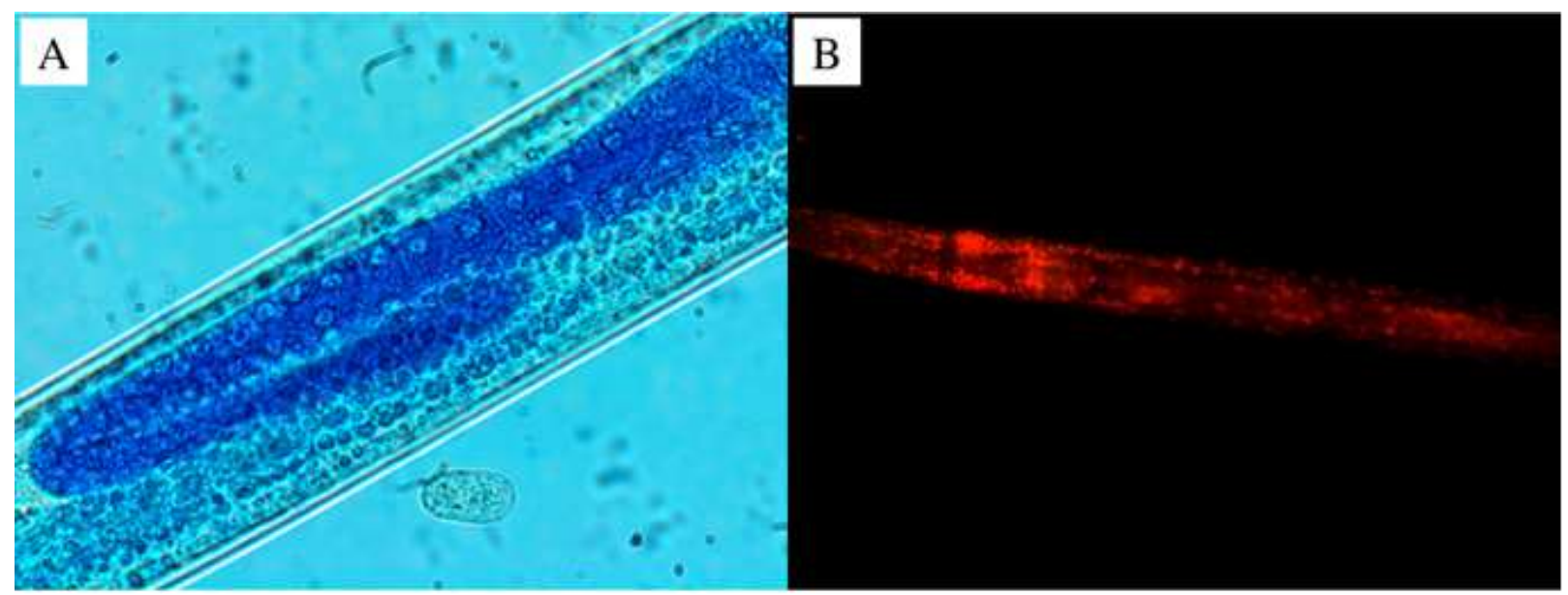

Fonte: Autores (2022).

Os Panagrellus redivivus são vermes de reprodução sexuada que, obrigatoriamente, envolve a participação de machos e fêmeas produtores de gametas (Hechler, 1970). Quando a fecundação ocorre, os gametas são unidos originando o ovo ou zigoto. Este sofre uma série de divisões mitóticas resultando em numerosas células que, posteriormente, se diferenciam para formar os diversos tecidos e órgãos do novo indivíduo, o embrião (Quesado, Cavalcante \& Menezes, 1996).

Após a fecundação, o zigoto se divide em duas células, que se dividem em quatro e assim sucessivamente. A cada 
divisão, as células se tornam menores e mais numerosas (Quesado, et al., 1996). A visualização desse processo é muito fácil utilizando como modelo o $P$. redivivus. Fêmeas adultas possuem ovos em todos os estágios de desenvolvimento dentro do útero (Figura 6). Na parte anterior, próximo a boca, estão os ovos durante as fases iniciais da embriogênese com células se dividindo para a formação do zigoto (Figura 6.A). Na parte posterior, próximo à vulva, estão os embriões com formação avançada (Figura 6.B). A observação da embriogênese em P. redivivus permite a compreensão da formação de um novo ser vivo por divisões consecutivas a partir de células pré-existentes.

Figura 6. Embriogênese em Panagrellus redivivus. A) primeiras divisões celulares. B) embrião formado.

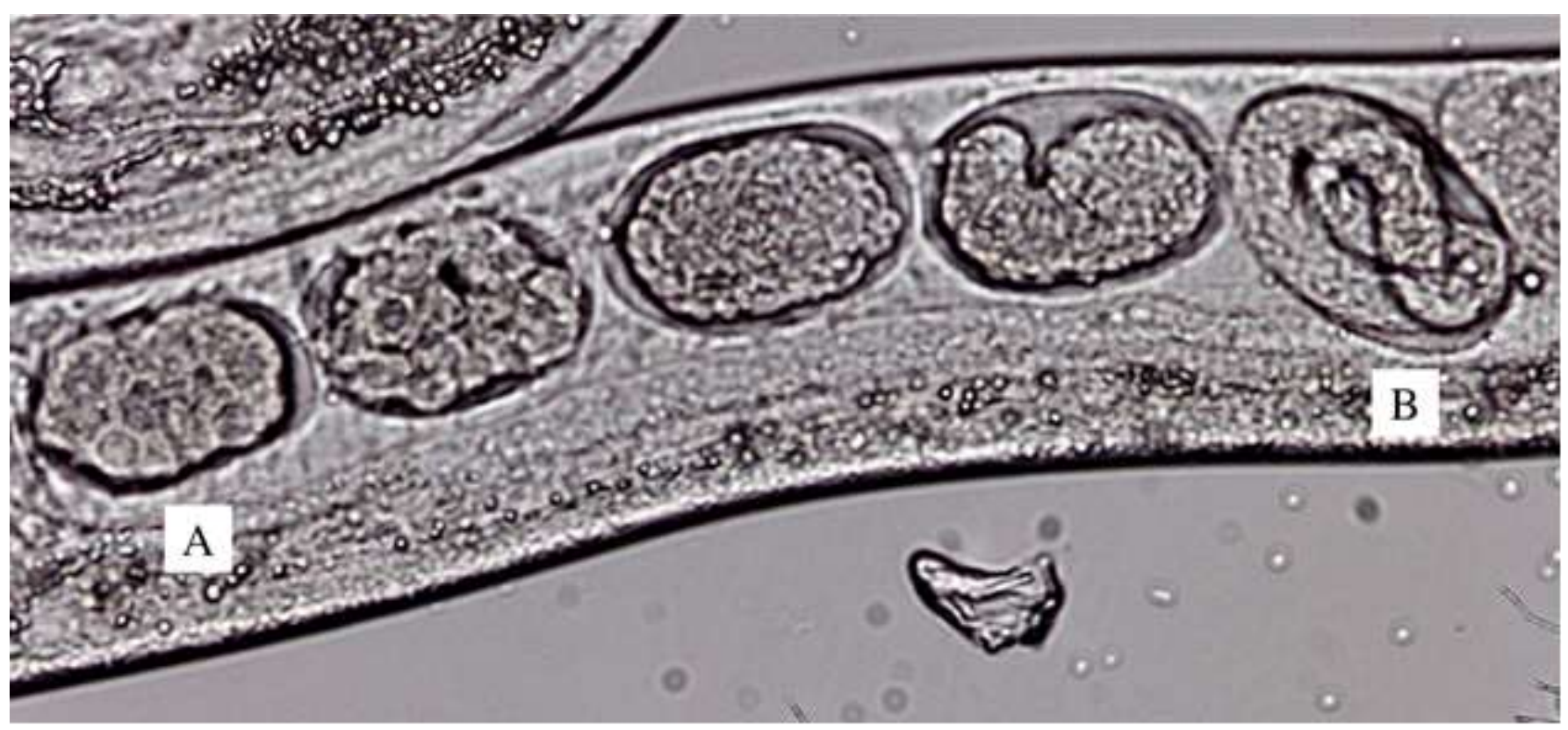

Fonte: Autores (2021).

Quesado et al. (1996) propõem uma aula prática sobre embriogênese utilizando como modelo o nematoide Rhabdias bufonis, um parasita do pulmão de sapos e outros anfíbios. Também possui coloração clara e desenvolvimento dentro do útero materno. Contudo, as fêmeas desta espécie contendo ovos em seu útero apenas são encontradas no pulmão de sapos. Além disso, $R$. bufonis são parasitas obrigatórios, ou seja, apenas completam seu ciclo de vida após passagem pelo hospedeiro. Sendo assim, a obtenção do material para essa aula prática envolveria o sacrifício de muitos anfíbios até que um animal parasitado fosse encontrado. Por outro lado, a utilização de P. redivivus é mais fácil, uma vez que esses animais podem ser obtidos pelo comércio eletrônico (E-commerce) e cultivados em laboratório.

O estudo da biologia celular é tão importante quanto encantador. Entender o funcionamento das estruturas, bioquímica e divisão celular é fundamental para a compreensão de conceitos mais complexos relacionados à anatomia, fisiologia, reprodução, hereditariedade, combate e prevenção de doenças e até mesmo à ecologia. Sendo assim, a realização de estudos teóricos críticos e reflexivos é fundamental. Contudo, a realização de atividades práticas que contextualizam, integram o aluno a construção do conhecimento e estimulam o pensamento científico também são fundamentais. Para Morán (2015) a melhor forma de aprender é combinando equilibradamente atividades, desafios e informações contextualizadas. Ainda segundo esse autor, a aprendizagem escolar é como dirigir um carro. Para aprender a dirigir, não basta ler muito sobre esse tema; tem que experimentar, rodar com o ele em diversas situações com supervisão, para depois poder assumir o comando do veículo sem riscos. 


\section{Conclusão}

Esse estudo propõe o uso de Panagrellus redivivus como modelo experimental para aulas práticas de biologia celular. O nematoide em questão é usado frequentemente em aquariofilia como alimento para peixes e crustáceos. Por isso, pode ser obtido tanto em lojas do ramo quanto no comércio online por valores acessíveis. $P$. redivivus também pode ser cultivado em meios de baixo custo, com farinha de aveia e água. Frente a isso, o cultivo do nematoide é possível de ser feito em laboratórios escolares.

Além de ser um material de fácil obtenção, baixo custo de cultivo e manejo simples, $P$. redivivus também é uma excelente ferramenta para o ensino da multicelularidade e da embriogênese. Dado sua transparência, a observação das células pode ser feita dispensando coloração. Assim, o aluno consegue acompanhar um dos preceitos básicos da teoria celular, o de que todo o ser vivo é formado por células. Concomitantemente, por serem animais de fecundação, desenvolvimento e eclosão interna (dentro do útero da fêmea), os processos de clivagem, formação do zigoto e desenvolvimento do embrião são perfeitamente observáveis. Ao acompanhar as etapas da embriogênese, o estudante é capaz de relacionar suas observações práticas a um segundo postulado da teoria celular: uma célula se origina de outra pré-existente.

$P$. redivivus é, portanto, um promissor nematoide para o ensino de biologia celular. Seu custo de obtenção e cultivo é baixo, mas a contribuição na aprendizagem é muito grande. Por meio de sua observação é possível elucidar os conceitos básicos da teoria celular. Além de estimular a reflexão, o pensamento e o trabalho científico. Afinal, cientistas não são criados ou inventados. Eles são formados por meio do incentivo ao estudo e a prática da ciência, o que deve acontecer desde o ensino básico.

\section{Agradecimentos}

Os autores agradecem a Pró-Reitoria de Graduação, UFSM, que através do programa FIEX (projeto 056399), proporcionaram as condições para a realização desse trabalho.

\section{Referências}

Abolafia, J., Alizadeh, M., \& Khakvar, R. (2016). Description of Panagrellus ulmi sp. n. (Rhabditida, Panagrolaimidae) from Iran, and comments on the species of the genus and its relatives. Zootaxa, 4162(2), 245-267. http://doi.org/10.11646/zootaxa.4162.2.3

Alberts, B., Bray, D., Hopkin, K., Johnson. A., Lewis, J., Raff, M. \& Walter, P. A. (2017). Fundamentos da Biologia Celular. Artmed.

Borges, T. S., \& Alencar G. (2014). Metodologias ativas na promoção da formação crítica do estudante: o uso das metodologias ativas como recurso didático na formação crítica do estudante do ensino superior. Cairu em Revista, 3(4), 119-143. https://www.cairu.br/revista/arquivos/artigos/2014_2/08\%20METODOLOGIAS\%20ATIVAS\%20NA\%20PROMOCAO\%20DA\%20FORMACAO\%20CRITI CA\%20DO\%20ESTUDANTE.pdf

Caputo, L. F. G., Gitirana, L. B., \& Manso, P. P. A. (2010). Técnicas histológicas. In Monilaro, E. M., Caputo, L. F. G. \& Amendoeira, M. R. R. (Org.), Conceitos e métodos para a formação de profissionais em laboratórios de saúde (Vol.2, Cap.3, pp. 89-188). EPSJV/IOC.

Carlan, F. A., Sepel, L. M. N., \& Loreto, E. L. S. (2014). Teaching Cell Biology in Primary School., Education Research International. 2014: Article ID 272475,2014. 10.1155/2014/272475

Costa, J. L., \& Frenedozo, R. C. (2020). Metodologias ativas nas atividades investigativas em aulas de Biologia. (Dissertação de Mestrado). Universidade Cruzeiro Do Sul, São Paulo, Brasil.

Fernandes, M. G., Vaini, J. O., Crispim. B. A., \& Teixeira, T. Z. (2017). Práticas de biologia celular. UFGD.

Ferris, H. (2012). The beer mat nematode, Panagrellus redivivus: A study of the connectedness of scientific Discovery. Journal of Nematode Morphology and Systematics, 12(1), 19-25. https://revistaselectronicas.ujaen.es/index.php/jnms/article/view/769

Focken, U., Schlechtriem, C., Wuthenau, M., García-Ortega, A., Puello-Cruz, A., \& Becker, C. (2006, 08 de setembro). Panagrellus redivivus mass produced on solid media as live food for Litopenaeus vannamei larvae. Aquaculture Research, 37(14), 1429-1436. 10.1111/j.1365-2109.2006.01578.x

Freitas, D. F. (2017). Caracterização e produção de melanina pelo fungo Nematófago duddingtonia flagrans e avaliação da sua participação na atividade predatória (Tese de Doutorado). Universidade Estadual do Norte Fluminense, Campos dos Goytacazes, Brasil. 
Research, Society and Development, v. 11, n. 2, e29311225629, 2022

(CC BY 4.0) | ISSN 2525-3409 | DOI: http://dx.doi.org/10.33448/rsd-v11i2.25629

Hechler, H. C., (1970). Reproduction, Chromosome Number, and Postembryonic Development of Panagrellus redivivus (Nematoda: Cephalobidae). Journal of Nematology, 2(4), 355-361. Recuperado de https://journals.flvc.org/jon/article/view/64615

Ivanova, E., Perfilieva, K., \& Spiridonov, S. (2018). Panagrellus levitatus sp. n. (Rhabditida: Panagrolaimidae), a nematode suppressing Drosophila melanogaster in laboratory cultures. Nematology, 20(3), 285-297. 10.1163/15685411-00003141

Lavens, P., \& Soorgelos, P. (1996). Manual on the production and use of live food for aquaculture. FAO.

Morán, J. (2015). Mudando a educação com metodologias ativas (Coleção Mídias Contemporâneas. Convergências Midiáticas, Educação e Cidadania: aproximações jovens). UEPG/PROEX.

Nadler, S.A., Ley, P., Mundo-Ocampo, M., Smythe, A. B., Stock, S. P., Bumbarger, D. \& Baldwin, J. G. (2006). Phylogeny of Cephalobina (Nematoda): Molecular evidence for recurrent evolution of probolae and incongruence with traditional classifications. Molecular Phylogenetics and Evolution, 40(3), 696711. 10.1016/j.ympev.2006.04.005

Oliveira, M. A. F., Andrade, L. C. R., \& Araújo V. R. (2019, outubro). Reflexões sobre a importância das práticas de microscopia no conteúdo de biologia celular no ensino médio. In Anais do VI Congresso Nacional de Educação. Fortaleza, Brasil.

Paim, M.G, Goldschmidt, A.I., \& Loreto, E.L.S., (2021) Concepções prévias de alunos do 9o ano do Ensino Fundamental sobre o processo de cicatrização e sua relação com a Biologia Celular. Research, Society and Development 10 (8), e10610817000. 10.33448/rsd-v10i8.17000

Quesado, H. L. C., Cavalcante, M. P. P., \& Menezes, M. F. F. (1996). Biologia práticas. Fortaleza, Brasil: EUFC.

Radwin, I. A., \& Rouse, D. B. (1990). Communications: Yield characteristics of the free-living nematode Panagrellus redivivus in different culture media. The Progressive Fish-Culturist, 52(4), 237-240. 10.1577/1548-8640(1990)052<0237:CYCOTF $>2.3 . C O ; 2$

Sautter, J., Kaiser, H., Focken, U., \& Becker, K. (2007, 3 de maio). Panagrellus redivivus (Linné) as a live food organismin the early rearing of the catfish Synodontis petricola (Matthes). Aquaculture Research, 38(6), 653-659. 10.1111/j.1365-2109.2007.01714.x

Souza, A. C. (2013). A experimentação no ensino de ciências: importância das aulas práticas no processo de ensino aprendizagem (Monografia de Especialização). Universidade Tecnológica Federal do Paraná, Medianeira, Brasil.

Stock, S.P., \& Nadler, S. A. (2006). Morphological and molecular characterisation of Panagrellus spp. (Cephalobina: Panagrolaimidae): taxonomic status and phylogenetic relationships. Nematology, 8(6), 921-938. https://brill.com/view/journals/nemy/8/6/article-p921_11.xml?rskey=VOJhfX\&result=1 